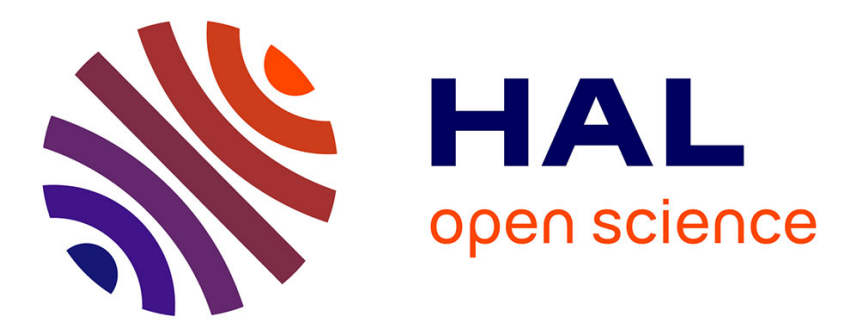

\title{
A Blockchain Application Supporting the Manufacturing Value Chain
}

\author{
Bjørn Jæger, Terje Bach, Simen Alexander Pedersen
}

\section{To cite this version:}

Bjørn Jæger, Terje Bach, Simen Alexander Pedersen. A Blockchain Application Supporting the Manufacturing Value Chain. IFIP International Conference on Advances in Production Management Systems (APMS), Sep 2019, Austin, TX, United States. pp.466-473, 10.1007/978-3-030-30000-5_58 . hal-02419193

\section{HAL Id: hal-02419193 \\ https://hal.inria.fr/hal-02419193}

Submitted on 19 Dec 2019

HAL is a multi-disciplinary open access archive for the deposit and dissemination of scientific research documents, whether they are published or not. The documents may come from teaching and research institutions in France or abroad, or from public or private research centers.
L'archive ouverte pluridisciplinaire HAL, est destinée au dépôt et à la diffusion de documents scientifiques de niveau recherche, publiés ou non, émanant des établissements d'enseignement et de recherche français ou étrangers, des laboratoires publics ou privés. 


\title{
A blockchain application supporting the manufacturing value chain
}

\author{
Bjørn Jæger ${ }^{[0000-0002-4661-5102]}$, Terje Bach ${ }^{[0000-0001-6659-1622], ~ a n d ~ S i m e n ~ A l e x a n d e r ~}$ \\ Pedersen
}

\begin{abstract}
Molde University College, Specialized University in Logistics, Molde, Norway
\{bjorn.jager, terje.bach\}@himolde.no, simenpede@gmail.com
\end{abstract}

\begin{abstract}
Blockchain applications supporting the manufacturing value chain are beginning to appear; early adaptors are testing blockchain technology for applications like trace and track, life cycle management by digital twins, protection of intellectual property rights, enforcement of licensing agreements, and trading platforms for 3D printed parts. The aim of this paper is to discuss the use of blockchain applications in the value chain of manufacturers followed by a case study of a blockchain application used in the value chain of a Norwegian furniture manufacturer involving the manufacturer, a third-party service provider, a retailer, and the end-customer. The application supports a product configurator providing product selection and customization, a delivery planner and a product tracker using an open public blockchain for inter-organizational data-sharing.
\end{abstract}

Keywords: Manufacturing Value Chain, Inter-Organizational Processes, Blockchain.

\section{Introduction}

This paper presents a case study using blockchains to support business-to-business operations. The complexity of business networks makes interoperability across organizations a challenging task. Blockchains have been seen as a potential solution to enforce intellectual property rights of information, as well as offering a way of sharing information in a network without mutual trust between the parties. It is based on algorithms that lead to consensus among the network nodes and market mechanisms that motivate the nodes to behave in a non-opportunistic manner [1]. This is recognized by the business environment as well as the research community as illustrated by the quote from Mendling et al.: "the emerging blockchain technology has the potential to drastically change the environment in which inter-organizational processes are able to operate" [1].

For companies, this puts forward a need to explore blockchain technologies for their external business operations. This paper presents the use case of how a furniture manufacturing company explore blockchain technologies for tracking furniture in their distribution chain consisting of a third-party service provider, a retailer, and an end-customer. 


\section{Literature review}

\subsection{Blockchains}

A blockchain, is an overlay network on top of the internet. The blockchain technology is the underlying technology for the Bitcoin cryptocurrency designed by [2] who stated that the purpose of the Bitcoin cryptocurrency was "A purely peer-to-peer version of electronic cash would allow online payments to be sent directly from one party to another without going through a financial institution.". The design was realized shortly after when the original Bitcoin network started on January 3, 2009. The network has since then seen a rapid growth, both in value and in the number of transactions, and a lot of other blockchain-based networks are being developed and deployed.

This paper is based on the use of an open public blockchain (OPBC). Any OPBC could be used, but we selected the latest version of the original blockchain by Nakamoto, the Bitcoin Satoshi's Vision called Bitcoin SV [3] [4]. The main reasons for using an OPBC are; they include a free, open for all, and shared distributed database infrastructure on top of the internet, they become more reliable as they grow, they are immutable for all practical purposes, they can store arbitrary data including user-defined computer programs (smart contracts) using Bitcoin script, and they have an embedded run-time environment that executes the smart contracts stored in the blockchain [5].

\subsection{Inter-Organizational Processes}

Recent developments show a growing erosion of traditional organizational bounds [6]. Work is mostly done within organizations. However, work can increasingly be coordinated through formal arrangements among institutions like consortia, institutes, and partnerships, and through more informal communities of practice, and multi-team systems that cross or even exist outside of the boundaries of traditional organizations. As an example, consider the manufacturing industries. A single company traditionally executed the major portion of manufacturing operations needed to create a final product [7]. Over the years, companies found it cost efficient to specialize in core competencies while outsourcing supporting activities, and thus adding an increasing number of connections, resulting in a global network of manufacturers. Now the major part of a product comes from many collaborating manufacturers, as can be seen from the large portion of the value creation that goes to purchasing. The 2.1 million enterprises classified as manufacturers in the European Union, spent on average $74 \%$ of their turnover on purchases of goods and services [8]. Hence, the manufacturing of products has become a networking endeavor.

However, these business-to-business network operations are not supported by standard information system solutions. Business-to-business operations involve a myriad of companies and organizations, manufacturers, third-party logistics providers (3PLs), freight forwarders, transportation providers, banks, insurance companies, and authorities. While ERP systems support and automate the business processes of each enterprise, the support and automation of business-to-business processes of the extended 
value network are missing. Contemporary networked operations depend on partly manual processes involving spreadsheets, email, Electronic Data Interchange (EDI) and proprietary software solutions. Integration, synchronization and a system of record and transparency that are taken for granted within enterprises by ERP systems are not attended to in a systematic manner in the external value network. Any changes in the business-to-business operations are costly to follow up on for trading partners. The data latency is high, and the ERP systems of companies involved must be consolidated and eventual disputes resolved $[9,10]$. IBM reports that they need to resolve around 27000 disputes yearly related to invoices alone in their financial service sector, even if that amounts to just under $1 \%$ of the total number of invoices handled per year, the cost is substantial since they require manual intervention and delay [11].

In analogy with ERP systems for intra-organizational process integration and data sharing, the open public blockchain can be seen as a database shared among companies for inter-organizational process integration and data sharing.

\section{Case Study}

\subsection{Background}

Ekornes ASA is the largest furniture manufacturer in Norway and owns such brand names as Ekornes ${ }^{\odot}$, Stressless ${ }^{\odot}$, Svane $^{\odot}$, and $\mathrm{IMG}^{\odot}$. Manufacturing takes place at the group's nine factories, five of which are located in Norway, one in the USA, two in Thailand and one in Vietnam. Ekornes was acquired by Qumei Home Furnishing Group in 2018 [12].

Ekornes has an ongoing project to establish a new digital platform that will allow them to showcase products online, either through their own websites or through their distributors' websites. The platform is intended to enable online sales of products as well, directly to customers, in combination with retailers, or completely through the retailer's online sales channels. Regardless of the sales channel selected, Ekornes has the strategy to establish a strong digital platform to support their retailers, while at the same time they prepare for direct communication with the end-customers both in sales and to gain insights into customer needs [12].

Ekornes started looking at the blockchain technology in 2018. They have been engaging master students to investigate the theme as their thesis topic, and Ekornes has started the development of a demonstrator as part of the business case presented here involving the use of blockchain technology partly funded by Manufacturing Networks 4.0, a research project by the Norwegian Research Council.

Ekornes has always been focused on adopting the latest technology to develop the company. The business idea is the development, manufacturing, and sale of furniture. They recognize the need to adopt new technology and new competence to stay competitive, especially regarding the fast progression of digitalization. Traditionally, Ekornes has been at the forefront with regards to the automation of production with extensive use of industrial robots. Now Ekornes believe the biggest benefits of digitalization are to be found on the sales side: 
"The customer's entire journey, from the moment she first becomes interested in a product until it has been bought and paid for, is changing radically as a result of digitalization. The first thing many people do now when they are looking to buy a new piece of furniture, is to scour the internet. Online sales of furniture are rising sharply. New players have entered the market, and existing players are evaluating new business models to adapt to this new reality." [12].

The actors in the value chain of Ekornes are the skin producers, the transporters, part producers, shipping companies, the logistics service providers, the retailers, the initial customers, and eventual second-hand customers, as illustrated in Fig. 1.

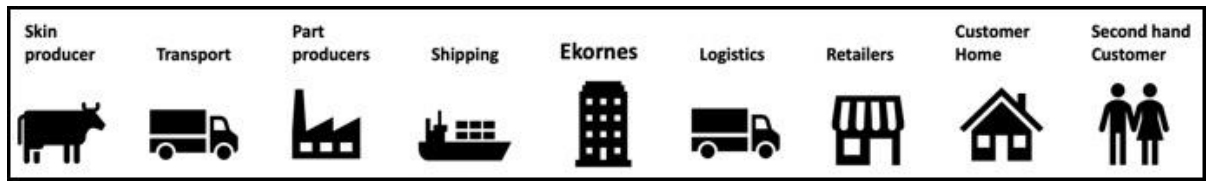

Fig. 1. The Ekornes Value Chain.

In light of the envisioned potential of blockchains for inter-organizational processes and the choice to focus on the sales side, Ekornes decided to explore blockchain in the distribution part of their blockchain. A case study was selected involving four actors in the distribution chain on the right side of Fig. 1; The Ekornes furniture manufacturer, a logistics service provider, a retailer, and an initial customer. Customers want to be able to customize their product and have an exact delivery date. This involves all four parties in the distribution chain. The manufacturer's production strategy is made-to-order for standard products giving delivery times of $4-6$ weeks. In addition, they offer a QuickShip segment for a smaller selection following the assemble-to-order strategy allowing delivery within 72 hours.

\subsection{The AS-IS Scenario}

During a workshop discussing potential use cases focusing on the end-customer's journey, the following scenario was described:

A store clerk working in the retail sector has attention given to the conversion process of getting them to select a product and then getting the selection converted to a payment. Visibility might help increase conversion. For some of the failed conversions, retailers lose the potential sales because they cannot provide detailed information on product variety and delivery dates at the point of sale. Take for example a customer who is at a store in a mall in Norway and has asked for item $A B C$, but that item is with the wrong material in the store and the time-to-delivery is given as a rough estimate of 4-6 weeks. Typically, this is a lost sale and the customer is leaving empty handed. (from workshop discussion).

The current AS-IS process is modeled in Fig. 2 and shows the steps involved in the end-customers journey when purchasing furniture. Each participating actor is represented in a separate lane and has full control of the activities within their lane. Dotted lines represent information flow and solid lines represent process flow. 
The end-customers journey starts when a potential customer visits the retailer with an interest in buying furniture. The furniture retailer representative greets the customer and provides product information on the availability and characteristics of the products of interest. The availability information is updated for each manufacturer on a weekly basis.

If the customer decides to order, the retailer subsequently orders by the manufacturer the same day by email. The manufacturer then confirms the order to the retailer by email the same or next day, together with an as-good-as-possible forecast for the delivery schedule. The retailer then forwards the information to the customer by SMS.

After a short delay, the manufacturer starts production and assembles the different components for shipment and orders transportation by the distributor, which picks up and deliver the order to the retailer. At the same time when the order is picked up; the manufacturer informs the retailer by email. If not previously agreed upon, the retailer contacts the customer and agrees on how to deliver the customer order, before the actual delivery takes place. The customer relates only to the retailer, preventing end-customer information from reaching the manufacturer.

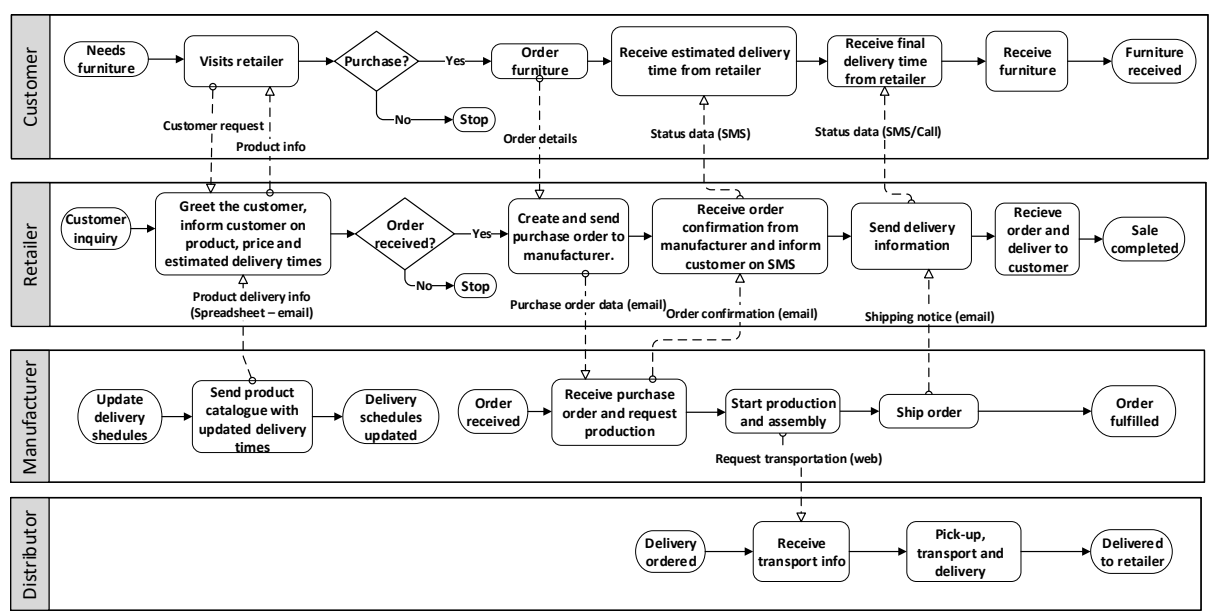

Fig. 2. Inter-organizational process diagram of the AS-IS scenario with each actor operating in a silo fashion with limited information exchange between each other.

\subsection{The TO-BE Scenario}

The TO-BE scenario starts as the AS-IS scenario, but after the last sentence "Typically, this is a lost sale and the customer is leaving empty-handed. ", the following scenario is added:

... With the right visibility tools, the salesperson can give detailed information on the optional materials and detailed delivery date for each selection. Now, when the customer looks disappointed the store clerk brings up the product configurator on his notepad and says "wait one second, I'll show you the optional materials together with a detailed delivery time for each option. And we'll give you a five percent discount for 
the inconvenience. Also, we support the QuickShip segment with delivery times within 72 hours ... and so on (from workshop discussion).

Based on this it was decided to build a demonstrator of a Product Configurator that would involve all the four parties. The traditional approach would be to build a portal or a hub to share data among the parties. This is costly, time-consuming and require testing. The parties can alternatively use the OPBC as a shared database. It is free, ready to use and very reliable. Thus, the Product Configurator should use an OPBC.

Using the Product Configurator, the sales clerk take the customer on a product tour. The sales clerk start by scanning the product of interest. The product, containing an NFC or a QR code with the unique product ID pops up in a web-app on a notepad. The customer selects options like the type of base, skin, textile, and color. When the product is configured as requested by the customer, the Sales Clerk retrieves exact delivery information directly from the producer. The Sales contract between the retailer and the customer is then ready to be completed directly from within the web-app.

The TO-BE process is modeled in Fig. 3 and from it is it clear that the start of the end-customers journey is near equal to the AS-IS scenario. However, we realize a significant difference in the way the retailer interacts with the customer through the Product Configurator which supports product selection and customization. Furthermore, the delivery planner functionality of the demonstrator ensures consistent delivery information retrieved directly from the manufacturers ERP system via the OPBC.

If the customer decides to place an order, the retailer subsequently places the order at the manufacturer by using the web-app, which store the complete order information as a transaction in the OPBC.

After receiving the customer order, the manufacturer allows for a short delay before the order is released to production and assembly. At any time, the customer and retailer might enquire for production milestones and delivery status via the web-app.

When the product is ready to be shipped, a transportation request is automatically sent to the distributor via the blockchain. The distributor pick-up the shipment and writes transactions into the $\mathrm{OPBC}$ at various handling points throughout the distribution process. These transactions can be viewed by all actors at any time.

After the shipment is delivered to the retailer's warehouse, the retailer arranges for the final delivery to the end-customer. A customer requests for a change in the delivery schedule can be handled directly from within the web-app. When the order is delivered to the end-customer, the warranty period is automatically started and registered in the blockchain. In this TO-BE scenario, the manufacturer does have access to end-customer information that can be used for future interactions and sales promotions via e.g. referrals with discounts. 


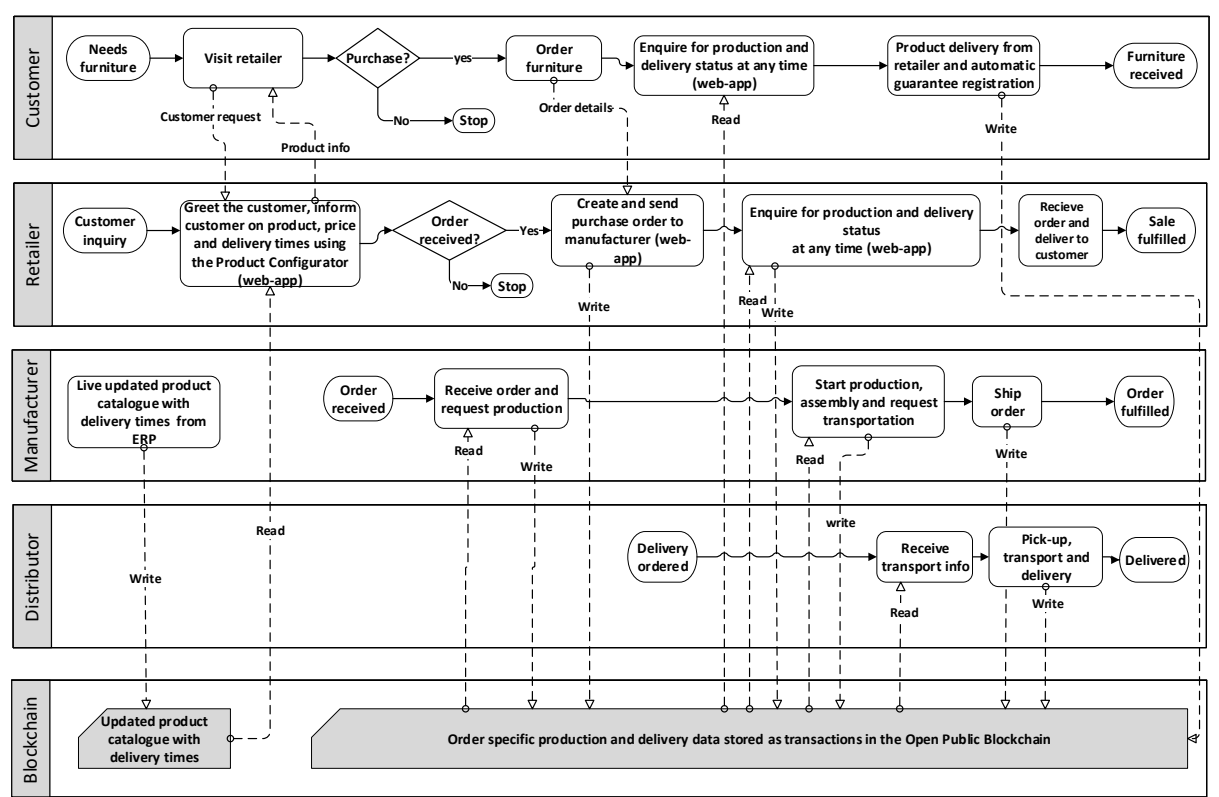

Fig. 3. Inter-organizational process diagram of the TO-BE scenario utilizing the open public blockchain as a shared data layer.

Both the AS-IS and the TO-BE process models are simplified for the sake of clarity. Some of the issues left out are the handling of payment, the various technologies and document formats for communication.

\section{Discussion}

The key differences between the scenarios are: In the AS-IS scenario no one has the full picture - information exists, however it is fragmented and spread between the actors. In addition, the information is uncertain since it must be updated through each process, e.g. delivery information requires multiple messages from retailer to the endcustomer, and delivery times are only updated on a weekly basis. The AS-IS problems include redundancy, lack of data control, a mix of interfaces, delays, lack of reliability and lack of data integration. In the TO-BE scenario, actors get exact information through the shared blockchain, including delivery times that is important for planning purposes and to increase the conversion rate of sales at retailers. If there is a need to keep the information secret, the information in the OPBC can be encrypted and keys distributed to actors that are granted access.

The use of a blockchain in this context might seem unnecessarily complex since the small number of actors of four gives little substantiation to justify the added value of using a blockchain. However, a blockchain based solution will be more useful as the number of participants increase, and since it is not controlled by any of the participants the risk of any partner exercising power over other partners is low, increasing the likelihood of the partners being willing to share information. The manufacturer in our case 
study had a need to build competence in a long-term perspective to explore models suitable for following a product through its entire life-cycle across multiple owners and users as part of their move towards sustainability by circular economy models.

\section{Conclusion}

This paper discussed the use of blockchains in the value chain of manufacturers including a case study of a blockchain application used in the distribution chain of a Norwegian furniture manufacturer involving the manufacturer, a third-party service provider, a retailer, and an end-customer. The application utilizes an open public blockchain as a shared data repository for integrating processes across the actors demonstrating how manufacturers can build competence and explore ways to support information sharing in business-to-business networks.

Acknowledgments. We thank the Manufacturing Network 4.0 project for support of the research presented in this paper.

\section{References}

1. Mendling, J., Weber, I., Aalst, W. V. D., Brocke, J. V., Cabanillas, C., Daniel, F., ... \& Gal, A. (2018). Blockchains for business process management-challenges and opportunities. ACM Transactions on Management Information Systems (TMIS), 9(1), 4.

2. Nakamoto, S. "Bitcoin: A Peer-to-Peer Electronic Cash System," 2008. bitcoin.org/bitcoin.pdf

3. Bitcoin SV. (2019) Vision. https://bitcoinsv.io/vision/

4. Buntinx, J. P. (2018) What is Bitcoin SV? Bitcoin Insider. www.bitcoininsider.org/article/51260/what-bitcoin-sv

5. Antonopoulos, A. M. (2017). Mastering Bitcoin: Programming the open blockchain. " O'Reilly Media, Inc."

6. O'Mahony, S., \& Lakhani, K. R. (2011). Organizations in the Shadow of Communities. In C. Marquis, M. Lounsbury, \& R. Greenwood (Eds.), Communities and Organizations. Research in the Sociology of Organizations. Emerald Group Publishing. vol, 33. (pp. 3-36).

7. Magal, S. R., Word, J. (2009) Essentials of business processes and information systems. Wiley Publishing. Eurostat. (2015).

8. Eurostat/European Commission: Statistics for the European Union's (EU) manufacturing sector. ec.europa.eu/eurostat/statistics-explained/index.php/Manufacturing_statistics__NACE_Rev._2\#Structural_profile

9. Nadler, J. (2001). Electronically-mediated dispute resolution and e-commerce. Negotiation Journal, 17(4), 333-347.

10. Savelyev, A. (2018). Copyright in the blockchain era: Promises and challenges. Computer law \& security review, 34(3), 550-561.

11. IBM-Blockchain, (2017). Real world examples of blockchain projects, www.youtube.com/watch? $v=w F y i S n G V 1 s c$

12. Ekornes. (2017). Annual report 2017. Available at http://ir.ekornes.com/ 